\title{
Fatigue Performance of Steel-Concrete Composite Continuous Box Girder Bridge Deck
}

\author{
Yuanxun Zheng $\mathbb{D}^{1},{ }^{1}$ Zhanlin Cao ${ }^{D},{ }^{1}$ Pan Guo $\mathbb{D D}^{1,2}$ Pu Gao, ${ }^{3}$ and Peng Zhang ${ }^{4}$ \\ ${ }^{1}$ School of Water Conservancy Science and Engineering, Zhengzhou University, Zhengzhou, Henan 450001, China \\ ${ }^{2}$ School of Civil Engineering, Zhengzhou University, Zhengzhou, Henan 450001, China \\ ${ }^{3}$ Technology Center, China Construction Sixth Engineering Division Corp., Ltd, Tianjin 300451, China \\ ${ }^{4}$ China Railway Engineering of Zhengzhou Seven Innings Group Co., Ltd., Zhengzhou, Henan 450052, China \\ Correspondence should be addressed to Pan Guo; 77741289@qq.com
}

Received 20 December 2020; Accepted 24 May 2021; Published 8 June 2021

Academic Editor: Mojtaba Ahmadieh Khanesar

Copyright (c) 2021 Yuanxun Zheng et al. This is an open access article distributed under the Creative Commons Attribution License, which permits unrestricted use, distribution, and reproduction in any medium, provided the original work is properly cited.

\begin{abstract}
The fatigue performance of the bridge deck significantly affects the safety and durability of the overall steel-concrete composite beam bridge. Based on the vehicle flow information of the highway within 10 years, the fatigue performance of a two-way fourlane steel-concrete composite continuous beam bridge deck is studied in this research. The results indicate that the effect of the wheel track position is negligible for two-way four-lane bridge when the wheel track sways laterally, and the fatigue stress of bridge deck concrete is the most unfavorable while the loading position is $7.0 \mathrm{~m}$ away from the bridge center line. The fatigue damage decreases by $30 \%-40 \%$ when the centerline of the lane deviates from the most unfavorable stress position by $1 \mathrm{~m}$. The punching fatigue of the concrete is more sensitive to the changes in slab thickness, and the thickness of the deck concrete slab is recommended to be $\geq 35 \mathrm{~cm}$.
\end{abstract}

\section{Introduction}

Compared with concrete bridges, steel-concrete composite structure bridges have the advantages of a lower self-weight and a larger span; compared with steel bridges, they have the advantages of less steel consumption, better structural stability, higher bending rigidity, and higher ductility [1-3]. However, steel-concrete composite beams are prone to fatigue problems under long-term repeated loading [2, 4-6]. The fatigue life of the welded joint-an important connecting part-has been studied extensively, and the fatigue problem is no longer a challenge $[7,8]$. Owing to the discontinuous stiffness at the crack, internal force redistribution and an uneven reinforcement force occur in the cracked composite beam. Therefore, fatigue problems tend to occur when the bridge deck operates with cracks $[9,10]$.

According to the existing research results, there is no relatively mature crack calculation theory for composite beams, and the test data about cracks of composite beams are also limited [11-20]. For example, Leonhardt et al. [11] performed fatigue tests on two composite beams with different strength connectors to study the slippage of welding nails in the negative-bending moment zone and the occurrence of cracks in concrete slabs. Zanuy et al. [14] obtained the calculation formula of the average strain of concrete cracks under fatigue load based on the tie-bar model and recommended the adoption of CEB-FIP and European standards. El-Zohairy et al. [20] showed that the degree of shear connection between steel beam and concrete deck played a major role in controlling longitudinal fatigue cracks of concrete deck.

In current research, structural fatigue assessment methods are mainly divided into two categories. The first category is assessment methods that do not calculate fatigue damage [21, 22]. This approach based on the maximum fatigue-load effect value obtained by loading the most unfavorable position is compared with the resistance value to assess the safety of the structure. The results obtained through this design method were conservative. 
The second type of the assessment method is the one that requires calculating the degree of fatigue damage [22-26]. It can be divided into two subcategories. The first design method is stress history process without calculating the fatigue details, such as the simple fatigue assessment method in the European Code [25], the AASHTO method in the United States [26], and the bike method in the British BS5400 [22]. This kind of method is similar to assessment without the fatigue damage in calculating the fatigue-load effect. The most unfavorable load-effect amplitude is determined by applying the fatigue load to bridges, the number of stress cycles is determined according to the traffic volume, and then the fatigue damage is calculated according to the fatigue cumulative damage principle to obtain the fatigue life corresponding to fatigue details. The second design method is a design method that needs to calculate the stress history process of fatigue details, e.g., the linear cumulative damage method [25] in the European Code, the fatigue assessment guidelines for road bridges in Japan, and the vehicle load spectrum method [22] in the British code BS5400. In this method, the stress spectrum of fatigue details is obtained by loading the influence line according to the fatigue load, and the stress frequency spectrum is obtained through counting methods (such as the rain-flow method or water-discharge method). Then, the fatigue damage degree is calculated according to Miner's linear cumulative damage principle, and a fatigue check is performed [27]. This loading mode reveals the process of fatigue damage and is more sophisticated than other methods.

The bridge deck directly bears vehicle loads; thus, its design affects the safety and durability of the overall bridge structure [28-30]. The position of the wheel load significantly influences the total strain/stress response, as well as the overall effect of the bridge deck. The local effect of the wheel load contributes significantly to the total strain/stress response, and the global effect may be negligible or significant, depending on the location $[31,32]$.

At present, research on the effect of the wheel position on the fatigue performance of bridge decks mainly focuses on steel decks [33-37]. For example, Zhou et al. [34] showed that the lateral position of a vehicle was very sensitive to the transverse stress of the steel bridge deck and the fatigue damage of key parts. Zeng et al. [35] showed that the cumulative effect of plastic deformation should be considered when analyzing the fatigue damage of the steel deck under a vehicle wheel load. Zhu et al. [33] studied the stress behavior and fatigue life estimation of the composite system of orthotropic steel deck (OSD) and ultrahigh performance concrete (UHPC) under concentrated wheel load by means of field monitoring and finite-element analysis. The results indicated that the stress value corresponding to the fatigue detail was sensitive to the transverse position of a single wheel load. Although in-depth studies have been conducted on the mechanical performance of concrete bridge decks $[32,38-40]$, the fatigue behavior of concrete slab of steelconcrete composite beam bridge under wheel load still needs further study.

Previous studies indicated that the reinforcement ratio of the bridge deck significantly affects the fatigue of the bridge deck [41-45]. Amir et al. [41] studied the effect of the reinforcement ratio on the transverse early cracking of a GFRP-RC bridge deck to evaluate the effect of noncorrosive glass fiber-reinforced polymer (GFRP) on the shrinkage performance of reinforced concrete (RC). Ghatefar et al. [42] conducted tests on a GFRP-RC bridge deck with a reinforcement ratio of $0.7 \%$ under freeze-thaw and dry-wet conditions. Su et al. [45] studied the effects of steel fiberreinforced concrete panels with different reinforcement ratios on the negative-bending performance of orthotropic steel-concrete composite beams. However, no in-depth studies have been performed on the fatigue performance of steel-concrete composite beams.

Thus, in the present study, the fatigue performance of the deck of the Dazhenggang steel-concrete composite continuous beam bridge on the Shanghai-Hangzhou Expressway was investigated. First, the fatigue assessment process of the bridge deck was determined. Second, a finite-element analysis model was established, and the fatigue evaluation parameters of the bridge deck were determined according to traffic flow data of the expressway for 10 years. Finally, the effects of the wheel transverse position, steel and concrete damage, lane location, deck reinforcement ratio, and deck thickness on the fatigue performance of steelconcrete composite beams were analyzed.

\section{Fatigue Assessment Process of Bridge Deck}

Various fatigue assessment methods are also applicable to punching fatigue of bridge decks [23, 24]. To accurately reflect the fatigue damage process, the method of calculating the fatigue detail stress history [46] was used to evaluate the fatigue of the bridge deck in this study, as shown in Figure 1. The steps for evaluating the fatigue damage of the bridge deck included the determination of the fatigue load, the calculation of the fatigue-load effect, and the calculation of the fatigue damage. The fatigue calculation of the steel bar was based on the fatigue vehicle, and the punching fatigue calculation of the concrete was based on the axle.

\section{Finite-Element Analysis}

3.1. Project Overview. As shown in Figure 2, the ShanghaiHangzhou Expressway is a part of Shanghai-Kunming Expressway G60. It starts from Shanghai Xinzhuang; passes through Minhang, Songjiang, Jinshan in Shanghai, Jiashan, Jiaxing, Tongxiang, Haining, and Yuhang in Zhejiang; and finally connects Pengbu town in the eastern suburb of Hangzhou to Hangzhou-Ningbo Expressway.

The Dazhenggang steel-concrete composite beam bridge $(2 \times 75 \mathrm{~m})$ of the Shanghai-Hangzhou Expressway is located between the Songjiang and Dayun toll stations. A total of $163,369,169$ passenger cars and 65,998,076 trucks passed the Dayun toll station of the Shanghai-Hangzhou Expressway in the 10-year study period. To facilitate the calculation and analysis, the vehicles are classified, as shown in Table 1. Model 1 is a two-axle vehicle weighing $<3$ tons, model 2 is a two-axle vehicle weighing $>3$ tons, model 3 is a three-axle vehicle, model 4 is a four-axle vehicle, model 5 is a five-axle 


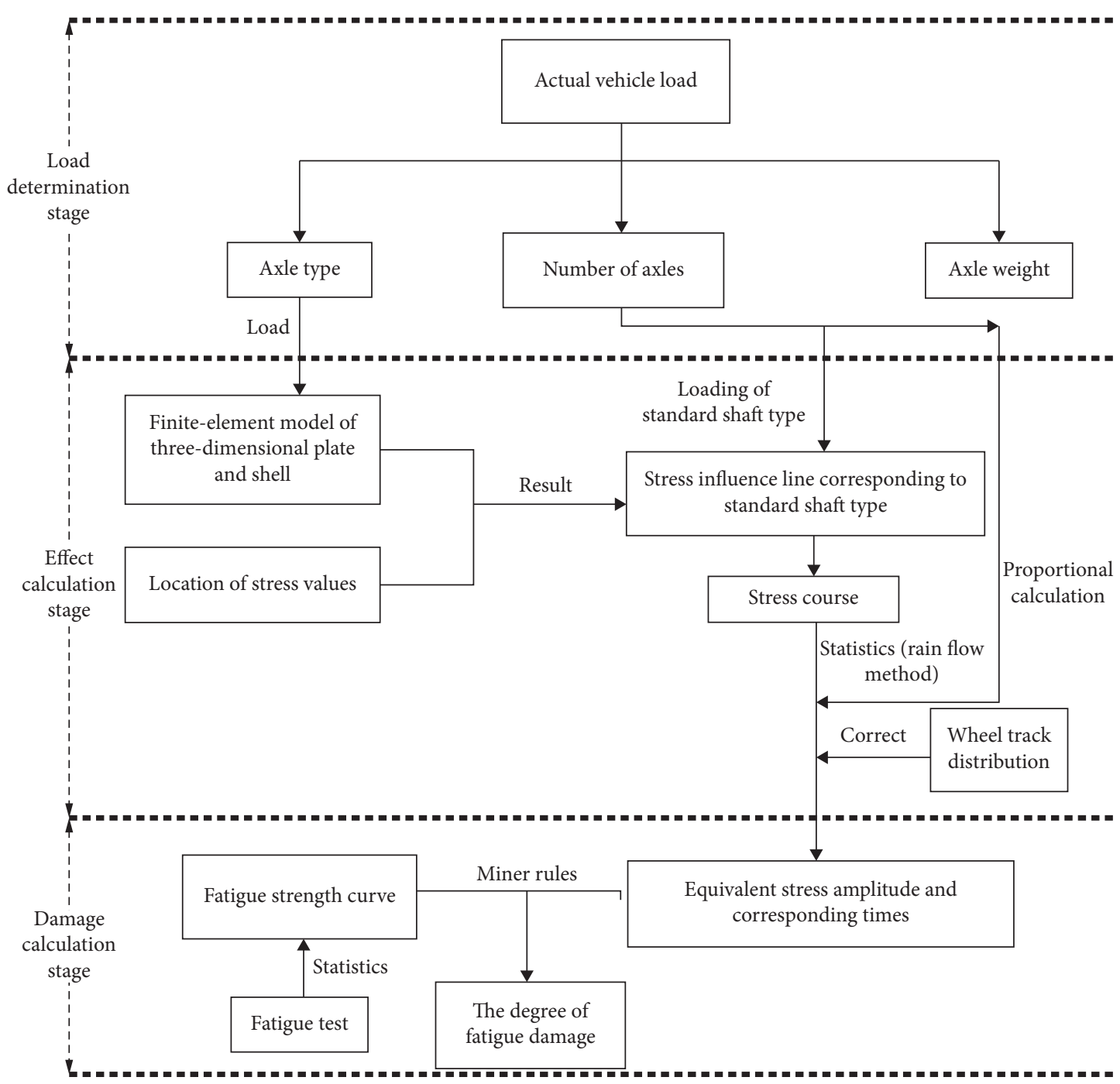

Figure 1: Fatigue damage assessment procedure for the bridge deck.

vehicle, and model 6 is a six-axle vehicle. As shown in Figure 3, two-axle vehicles weighing $<3$ tons were most common (78.1\%), followed by two-axle vehicles weighing $>3$ tons (9.8\%). Additionally, the number of five-axle large trucks was large $(6.4 \%)$.

3.2. Finite-Element Model. The bridge deck slab not only bears the local action of the vehicle but also participates in the force of the whole part as part of the composite beam. It is difficult to consider the effect of transverse beam on the supporting stiffness and shear lag of bridge deck when the simplified model is adopted, so it is impossible to accurately simulate the coupling effect of the first and second system models. The spatial finite-element model can reflect the actual stress state of the bridge [47]. The calculation model simulates the steel beam, concrete bridge deck, floor concrete, steel beam longitudinal and horizontal stiffener systems, and steel beam diaphragm systems.

The spatial force characteristics of the structure cannot be reflected accurately through the simplified method of effective distribution width $[48,49]$, and the finite-element method is used to simulate the spatial force characteristics of bridge in this study (Figure 4). The total of 132,503 units was divided in the finite-element model, and 22,634 spring units in each direction of $X, Y$, and $Z$ to simulate bond slip were included, and 64,601 concrete units and 45268 shell unites was used to simulate the main beam and profiled steel plate. The steel bars were dispersed in the concrete, and both steel bars and concrete adopt linear elastic constitutive relations. The modeling method was consistent with references [50], and the correctness of the model is ensured.

\section{Fatigue Assessment Parameters of Bridge Deck}

4.1. Fatigue Load. According to a traffic investigation and statistical analysis of Jiangyin Bridge over the Yangtze River, the Third Bridge of the Nanjing Yangtse River, Humen Bridge, and the Second Nanjing Yangtze Bridge, the fatigue design loads were determined, as shown in Figure 5. There were $202,793,690$ vehicles in the traffic volume survey data, $9,770,757$ in the vehicle weight survey data, 30,431,682 axles 


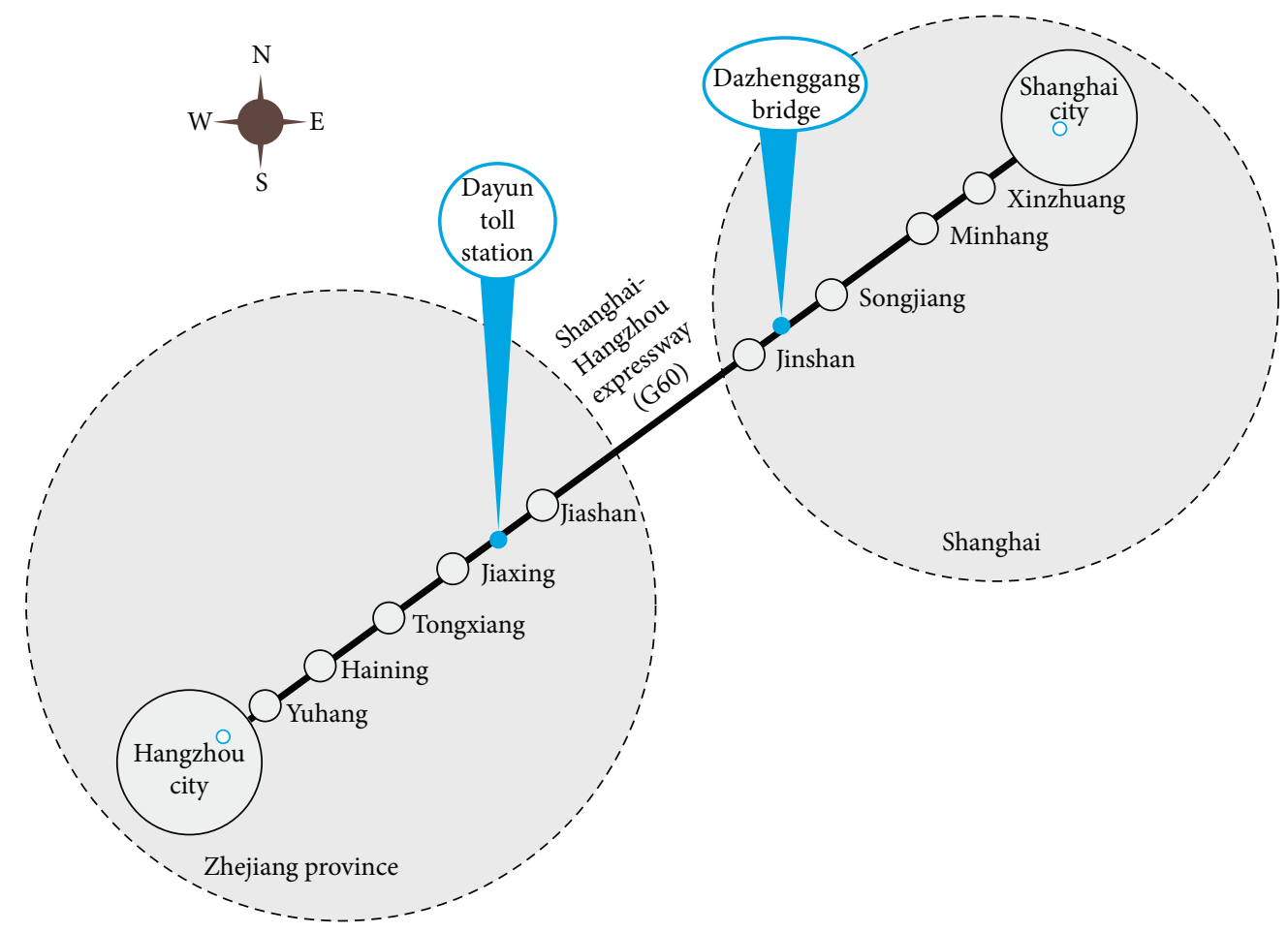

Figure 2: Location of Dazhenggang Bridge.

TABle 1: Vehicle type classification.

\begin{tabular}{|c|c|c|c|}
\hline Vehicle classification & \multicolumn{2}{|c|}{$\begin{array}{l}\text { Model } \\
\text { sketch }\end{array}$} & Vehicle type description \\
\hline Model 1 & \%o & ○० & Two-axle vehicle weighing $<3$ tons \\
\hline Model 2 & ○० & ○ & Two-axle vehicle weighing $>3$ tons \\
\hline Model 3 & \multicolumn{2}{|c|}{$\begin{array}{l}000 \\
000 \\
000\end{array}$} & $\begin{array}{l}\text { Single axle and two wheels + single axle and two wheels + single axle and four wheels } \\
\text { Single axle and two wheels + single axle and two wheels + single axle and four wheels } \\
\text { Single axle and double wheel + double axle and four wheels }\end{array}$ \\
\hline Model 4 & \multicolumn{2}{|c|}{$\begin{array}{l}8000 \\
0000\end{array}$} & $\begin{array}{l}\text { Single axle and two wheels + single axle and two wheels }+ \text { two axles and four wheels } \\
\text { Single axle and double wheel }+ \text { single axle and four wheels }+ \text { double axle and four wheels }\end{array}$ \\
\hline & \multicolumn{2}{|c|}{00000} & Single axle and double wheel + double axle and four wheels + double axle and four wheels \\
\hline Model 5 & \multicolumn{2}{|c|}{$\begin{array}{l}00000 \\
00000\end{array}$} & $\begin{array}{l}\text { Single axle and double wheel }+ \text { single axle and double wheel }+ \text { three axle and four wheels } \\
\text { Single axle and double wheel }+ \text { single axle and four wheel }+ \text { three axle and four wheels }\end{array}$ \\
\hline Model 6 & \multicolumn{2}{|c|}{000000} & Single axle and double wheel + double axle and four wheel + three axle and four wheels \\
\hline
\end{tabular}

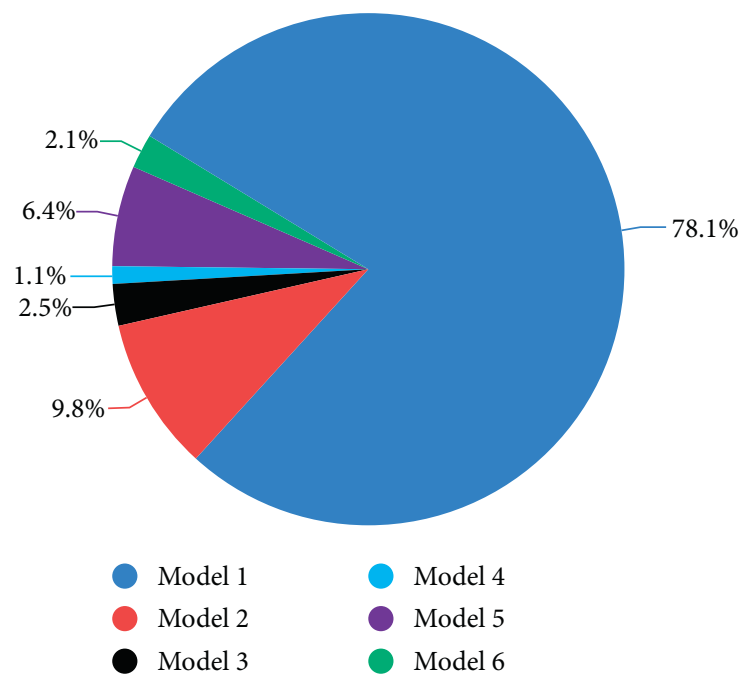

FIGURE 3: Proportions of different vehicle models. 


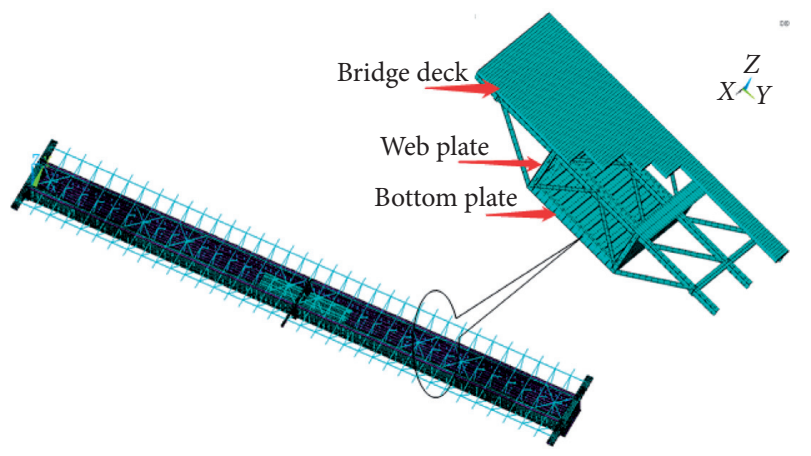

FIGURE 4: Finite-element model.

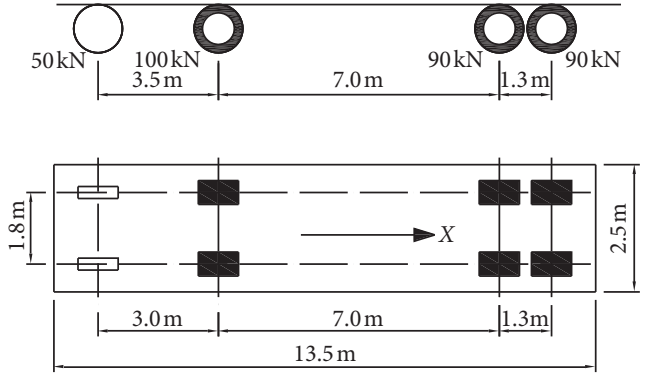

(a)

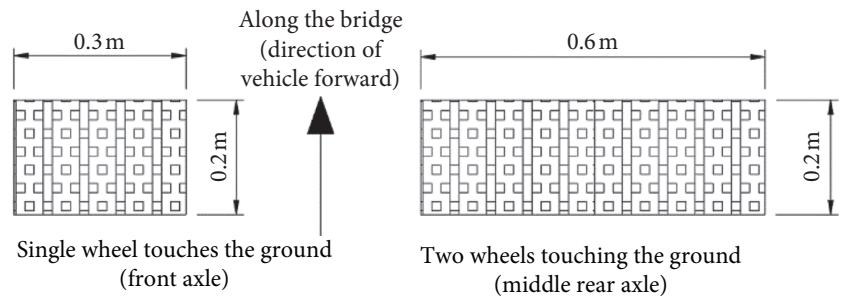

(b)

Figure 5: Fatigue design load model. Note: $\bigcirc$ indicates a single wheel on each side, $\bigcirc$ indicates two wheels on each side, and $\mathrm{X}$ refers to the direction along the bridge.

in the axle load survey data, and 11057903 axles spacing in the wheelbase survey data.

To better reflect the characteristics of the vehicle load on the Shanghai-Hangzhou Expressway, the traffic load of the Dazhenggang continuous composite beam bridge was converted into the fatigue design load, as shown in Figure 5. According to Miner's cumulative damage criterion [51],

$$
\sum n_{i} \times W_{i}^{3}=n_{f} \times W_{f}^{3},
$$

where $n_{f}$ is the equivalent number of vehicles under the fatigue design load, $W_{f}$ represents the vehicle weight of the fatigue design load model, which is taken as $330 \mathrm{kN}$, and $n_{i}$ represents the number of vehicles with weight $W_{i}$.

Let $N$ represent the total traffic flow, $P_{t i}$ represent the proportions of different vehicle types, and $P_{d i}$ represent the probability of the axle load distribution. $n_{i}$ and $n_{f}$ can be determined using the following formulas:

$$
\begin{aligned}
n_{i} & =N \times p_{t i} \times p_{d i}, \\
n_{f} & =\frac{\sum N \times p_{t i} \times p_{d i} \times W_{i}^{3}}{W_{f}^{3}} .
\end{aligned}
$$

According to the vehicle weight statistics for 474,660 vehicles that traveled on Jiangyin Bridge over the Yangtze River, the distribution and statistical characteristics of the vehicle weight for different vehicle types are presented in Figure 6 and Table 2. The equivalent number of vehicles

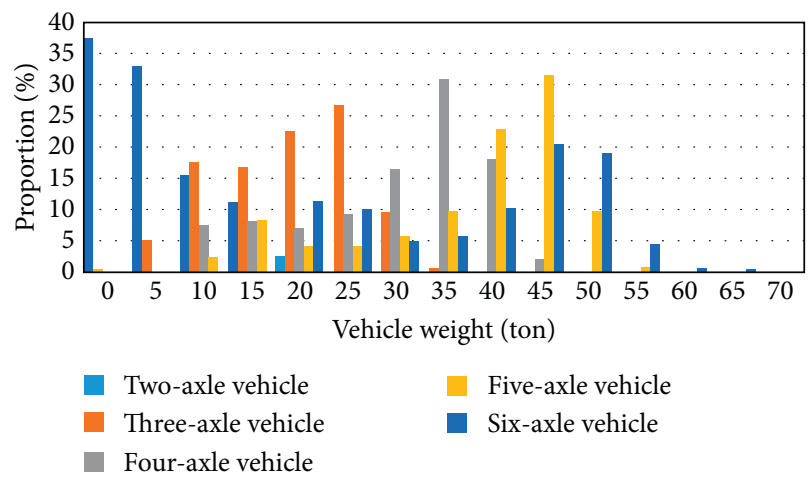

Figure 6: Weight distribution of vehicles that traveled on Jiangyin Bridge over Yangtze River.

corresponding to the fatigue design load for different vehicle types is presented in Table 3.

In this study, the distribution of vehicle types passing through the Dayun toll station is used to approximately replace the distribution of vehicle types passing through the Dazhenggang composite girder bridge in the ShanghaiHangzhou Expressway. The vehicle distribution is as follows: Model 1, 78.1\%; Model 2, 9.8\%; Model 3, 2.5\%; Model 4, 1.1\%; Model 5, 6.4\%; Model 6, 2.1\%; and vehicles weighing $>3$ tons, $21.9 \%$. Neglecting the effects of vehicles weighing $<3$ tons on the bridge fatigue, the equivalent vehicle conversion coefficient of the fatigue design load for vehicles weighing $>3$ tons can be obtained as follows: 
TABLE 2: Statistical characteristics of the vehicle weight.

\begin{tabular}{lcc}
\hline Vehicle type & Average vehicle weight (tons) & Variance of vehicle weight (tons) \\
\hline Two-axle vehicle & 8.89 & 4.92 \\
Three-axle vehicle & 21.54 & 6.93 \\
Four-axle vehicle & 32.25 & 8.85 \\
Five-axle vehicle & 39.87 & 10.42 \\
Six-axle vehicle & 38.71 & 12.87 \\
\hline
\end{tabular}

TABle 3: Equivalent number of vehicles corresponding to fatigue design load for different vehicle types.

\begin{tabular}{|c|c|c|c|c|c|}
\hline Vehicle weight & Vehicle type 2 & Vehicle type 3 & Vehicle type 4 & Vehicle type 5 & Vehicle type 6 \\
\hline $0-5 t$ & 0.001 & 0.000 & 0.000 & 0.000 & 0.000 \\
\hline $5-10 t$ & 0.004 & 0.001 & 0.000 & 0.000 & 0.000 \\
\hline $10-15 t$ & 0.009 & 0.010 & 0.004 & 0.001 & 0.000 \\
\hline $15-20 t$ & 0.017 & 0.025 & 0.012 & 0.012 & 0.017 \\
\hline $20-25 t$ & 0.008 & 0.072 & 0.023 & 0.013 & 0.036 \\
\hline $25-30 t$ & 0.001 & 0.155 & 0.054 & 0.024 & 0.059 \\
\hline $30-35 t$ & 0.000 & 0.092 & 0.158 & 0.056 & 0.046 \\
\hline $35-40 t$ & 0.000 & 0.013 & 0.454 & 0.144 & 0.086 \\
\hline $40-45 t$ & 0.000 & 0.001 & 0.389 & 0.491 & 0.217 \\
\hline $45-50 t$ & 0.000 & 0.000 & 0.057 & 0.941 & 0.615 \\
\hline $50-55 t$ & 0.000 & 0.000 & 0.004 & 0.393 & 0.766 \\
\hline $55-60 t$ & 0.000 & 0.000 & 0.000 & 0.046 & 0.238 \\
\hline $60-65 t$ & 0.000 & 0.000 & 0.000 & 0.003 & 0.048 \\
\hline $65-70 t$ & 0.000 & 0.000 & 0.000 & 0.002 & 0.036 \\
\hline $70-75 t$ & 0.000 & 0.000 & 0.000 & 0.004 & 0.008 \\
\hline Number of vehicles with equivalent fatigue & 0.038 & 0.369 & 1.156 & 2.131 & 2.173 \\
\hline
\end{tabular}

$\frac{(0.038 \times 9.8 \%+0.369 \times 2.5 \%+1.156 \times 1.1 \%+2.131 \times 6.4 \%+2.173 \times 2.1 \%)}{(21.9 \%)}=0.948$.

4.2. Axle Load Spectrum of Concrete Punching Fatigue Vehicle. For developing the axle load spectrum model, Jiangyin Bridge over Yangtze River, the Third Bridge of Nanjing Yangtse River, Humen Bridge, and the Second Nanjing Yangtze Bridge were taken as the research objects. The vehicle flow, vehicle axle load, wheelbase, and lane flow distribution were investigated and statistically analyzed. The axle load spectra for various vehicles (single axle and double wheel, single axle four-wheel, double axle, and triple-axle) were obtained, as shown in Figures 7-10.

The total axle load spectrum for all types of axles obtained from the statistical data is shown in Figure 11.

In this study, single-axle double-wheel, single axle fourwheel, double-axle, and three-axle units were converted to equivalent single-axle units according to the axle load. Models 1 and 2 are two-axle vehicles, while models 3-6 can be regarded as three-axle vehicles. According to the vehicle survey of the Dazhenggang Bridge, the number of axles (as shown in Table 4) can be determined. After the total vehicle axle number is determined, each axle load can be calculated according to the spectral value of the axle load.

\section{Analysis of Results}

5.1. Selection of Most Unfavorable Position of Lateral Force and Effect of Wheel Transverse Position. The fatigue failure of the $\mathrm{RC}$ bridge deck is mainly caused by the direct action of the wheels, and the stresses of the bridge deck at different transverse positions under the wheel load are not identical. To determine the most unfavorable position of the bridge deck, unit loads were arranged as close to each other as possible along the transverse direction of the bridge. The loading area was selected according to the provisions of the "General Design Specification for Highway Bridges" (JTGD60-015). A concentrated load of $100 \mathrm{kN}$ was applied, and the spacing was $0.5 \mathrm{~m}$ along the transverse direction of the bridge. The stress of the concrete slab under the wheel load was calculated under loading, and the accuracy was sufficient to satisfy the calculation requirements. The transverse load distribution is shown in Figure 12.

The bridge deck at the top of the bearing in the negativebending moment area was selected as the research object, as shown in Figure 13.

Vehicles do not drive exactly along the track line. Additionally, the distribution of the wheel track line along the transverse direction varies significantly among different countries; thus, it cannot be simply applied [52]. The Dazhenggang Bridge is a one-way four-lane bridge. According to statistics, the lateral swing range of centerline of the wheel track is approximately $1.5 \mathrm{~m}$ in the same lane. Considering the different stresses of the bridge deck caused by the wheel load in different transverse positions, the bridge deck $1.0 \mathrm{~m}$ from the centerline of the bridge was taken as the research object, and the horizontal spacing of $300 \mathrm{~mm}$ was 


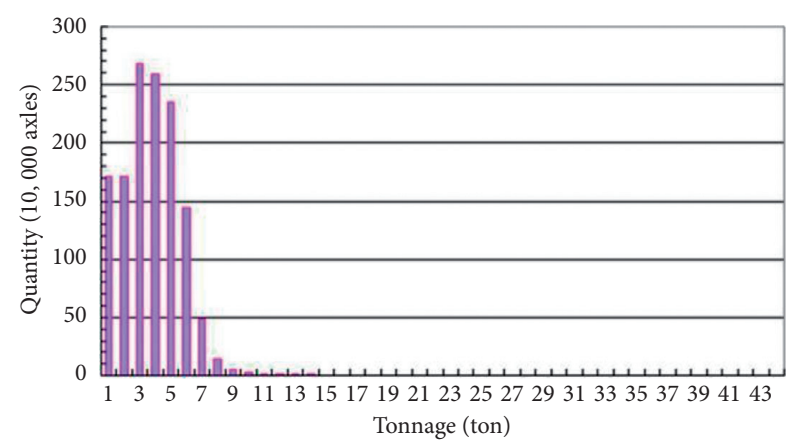

FIGURE 7: Single-axle and double-wheel load spectrum.

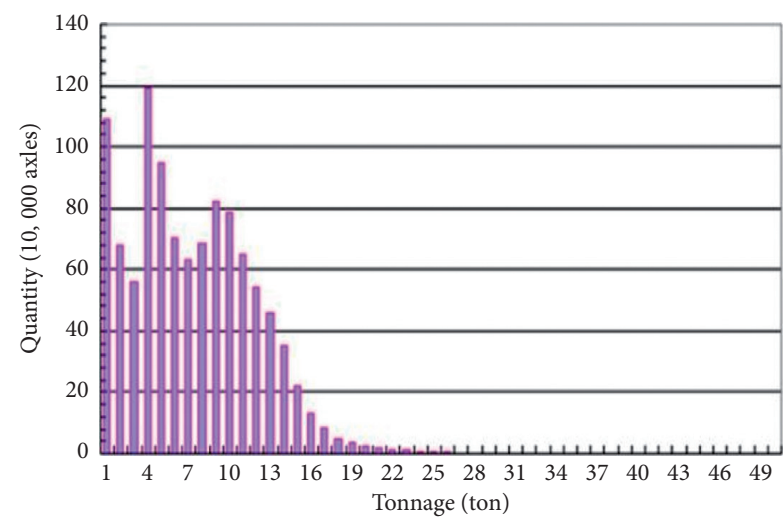

Figure 8: Single-axle four-wheel load spectrum.

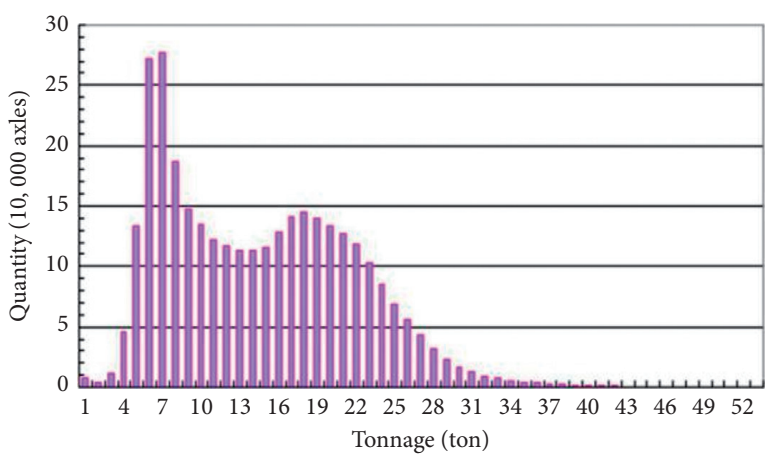

Figure 9: Double-axle load spectrum.

taken as a working condition. This was divided into five working conditions: path 0 , path -1 , path 1 , path -2 , and path 2. The transverse position of the bridge is shown in Figure 14. The frequency diagram of the corresponding vehicle transverse distribution is shown in Figure 15, and the effect of the wheel transverse position on the stress amplitude of the bridge deck is shown in Figure 16.

The influence lines of different positions of the wheels, i.e., the influence surface of the bending moment of the concrete slab, were used for calculation. To compare the effects of various wheel lateral distribution models on the roof stress amplitude, we refer to the calculation method for the equivalent stress amplitude [53] and consider the equivalent stress amplitude of the vehicle lateral distribution

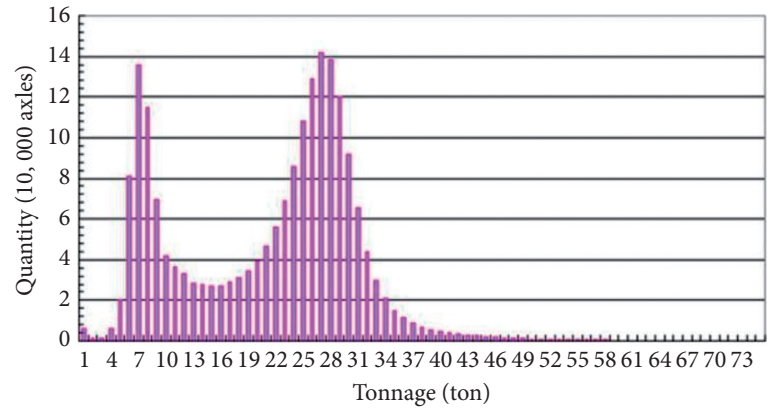

Figure 10: Triple-axle load spectrum.

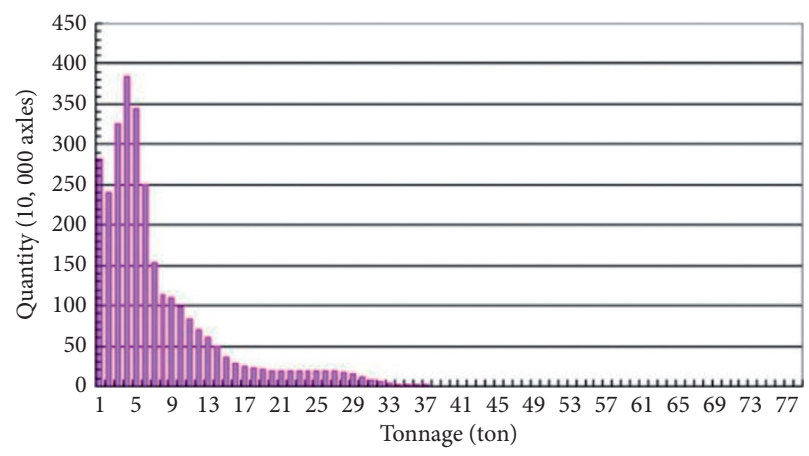

FIGURE 11: Total axle load spectrum.

TABle 4: Annual traffic volume and axle number for Dazhenggang Bridge.

\begin{tabular}{lccl}
\hline Years & Annual traffic volume & Number of axles & Remarks \\
\hline 2010 & $25,710,725$ & $57,052,099$ & \\
2020 & $43,460,505$ & $96,438,861$ & \\
2030 & $61,210,285$ & $136,000,000$ & Forecast \\
\hline
\end{tabular}

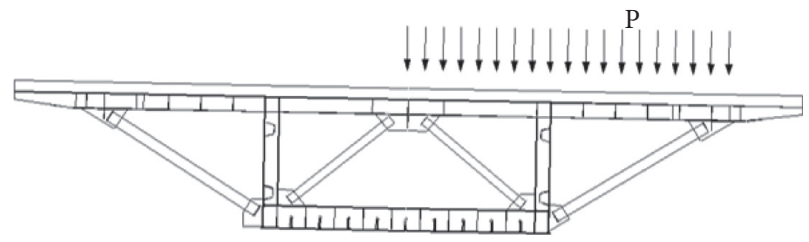

FIgURE 12: Transverse load distribution.

according to Miner's linear cumulative damage principle [54]. The equivalent calculation formula is as follows:

$$
\sigma_{s, \max }=\alpha_{E}^{f} \frac{M_{\max }^{f}\left(h_{0}-x_{0}\right)}{I_{0}^{f}},
$$

where $\Delta \sigma_{\text {eq }}$ represents the equivalent force amplitude; $\sigma_{s, \max }=\alpha_{E}^{f}\left(M_{\max }^{f}\left(h_{0}-x_{0}\right) / I_{0}^{f}\right)$ represents the probability corresponding to the $i^{\text {th }}$ wheel path (Figure 15); $\sigma_{s, \max }=$ $\alpha_{E}^{f}\left(M_{\max }^{f}\left(h_{0}-x_{0}\right) / I_{0}^{f}\right)$ represents the stress amplitude corresponding to the $i^{\text {th }}$ wheel path (Figure 16); and $\sigma_{s, \max }=$ 


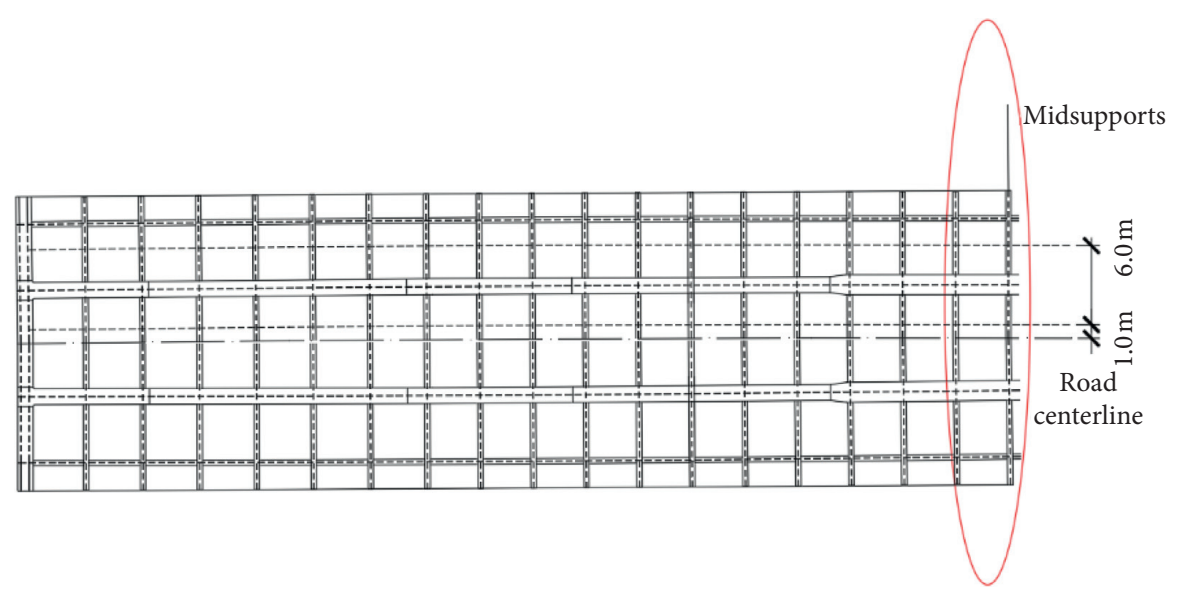

FIGURE 13: Checking the calculation position of the bridge deck in the negative-bending moment area.

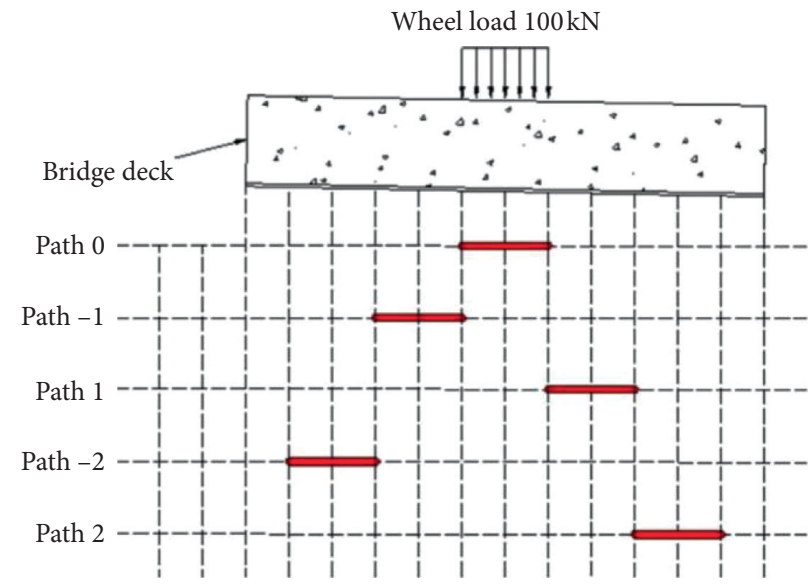

FIgURe 14: Lateral loading position of the wheel.

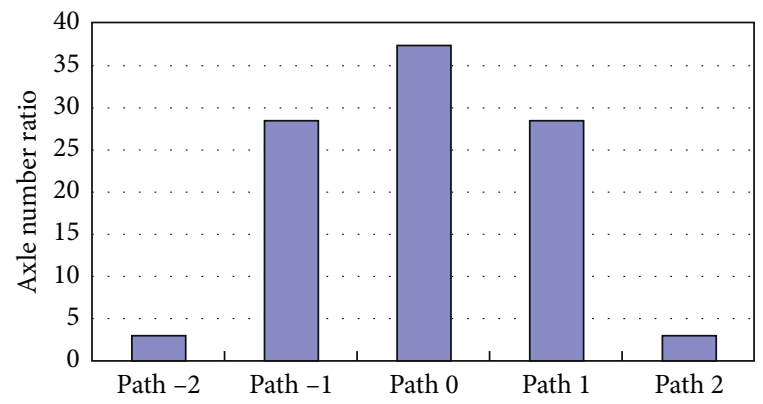

Figure 15: Lateral distribution frequency of vehicles.

$\alpha_{E}^{f}\left(M_{\max }^{f}\left(h_{0}-x_{0}\right) / I_{0}^{f}\right)$ represents the slope of the S-N curve, which is taken as 3 .

To better understand the differences between various wheel lateral distribution models and determine whether the effect of the bridge deck pavement on the lateral distribution effect of the wheels should be considered, the ratio of the equivalent stress amplitude calculated using the lateral distribution of the wheels to that calculated using the most unfavorable loading position was examined, as shown in Table 5. Because the performance of concrete bridge panels

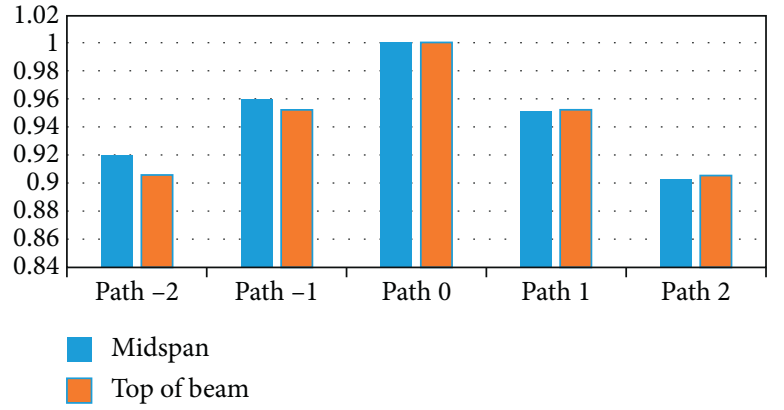

FIGURE 16: Effect of the wheel transverse position on the stress amplitude of the bridge deck.

Table 5: Equivalent stress-amplitude ratio.

\begin{tabular}{lc}
\hline & Equivalent stress-amplitude ratio \\
\hline Midspan & 0.913 \\
Beam & 0.907 \\
\hline
\end{tabular}

under a shared load is satisfactory and the swing of the wheel track has little effect on the stress of the bridge deck, the effect of the wheel track position was not considered in this study. 


\subsection{Damage to Reinforcement and Concrete of Bridge Deck}

5.2.1. Checking Calculation of Fatigue of Reinforcement. The traffic volume used for the fatigue checking of the reinforcing bars was the predicted traffic volume in Table 4 . There were four lanes in one direction. In the absence of lane distribution statistics, each lane was evenly allocated. During fatigue checking, it was assumed that vehicles weighing $<3$ tons did not cause fatigue damage to the steel bars. Therefore, these vehicles were not considered in the fatigue checking. A total of $21.9 \%$ of the vehicles in the traffic flow weighed $>3$ tons. According to the calculations and analysis presented in Section 3.1, each vehicle weighing $>3$ tons is equivalent to 0.948 fatigue vehicles.

The fatigue life of the bridge-deck reinforcement at different locations is presented in Table 6. According to calculations based on ECCS100 [25] and BS5400 [22], the fatigue life of the reinforcement at different locations is $>100$ years when the loading position is $1.0 \mathrm{~m}$ from the bridge centerline. According to ECCS100 [25], when the loading position is $7.0 \mathrm{~m}$ from the centerline of the bridge, the fatigue life of the cross-beam reinforcement is $>100$ years, while that of the midspan reinforcement is only 15 years. According to BS5400 [22], when the loading position is $7.0 \mathrm{~m}$ from the centerline of the bridge, the fatigue life of the cross-member reinforcement is 44 years and that of the midspan reinforcement is only 7 years. A comparative analysis revealed that the fatigue stress of the steel bar in the middle of the span is the most disadvantageous when the loading position is $7.0 \mathrm{~m}$ from the centerline of the bridge.

\subsubsection{Checking Calculation of Concrete Fatigue. For} checking the punching fatigue of the concrete, the axle load spectrum used was the number of axle loads converted from the traffic volume predicted in Table 4 . There were four lanes in one direction. At present, there are few provisions regarding the S-N curve of the punch-shear fatigue of concrete in national codes. It is generally considered that the punchshear fatigue resistance is related to the ratio of the section shear force to the maximum shear capacity. The results of Matsui [55] were used in the present study.

$$
\frac{P}{P_{s x}}=0.9565 N^{-0.0545} \text {. }
$$

Here, $P$ represents the punching shear and $P_{s x}$ represents the punching fatigue resistance of the sections. According to formula (6),

$$
P_{s x}=2 B\left(\tau_{p} x_{m}+\sigma_{t \max } C_{m}\right),
$$

where $B$ represents the slab width, $\tau_{p}$ represents the shear strength of the concrete, $\sigma_{t \max }$ represents the tensile strength of the concrete, $x_{m}$ represents the height of the compression zone, and $C_{m}$ represents the thickness of the protective layer of the steel bar. The tensile and compressive strengths of concrete are specified in the "Code for Design of Highway Reinforced Concrete and Prestressed Concrete Bridges and Culverts" (JTG 3362-2018). The shear strength was calculated using the formula developed by Guo and Xudong [56]:

$$
\tau_{p}=0.39 f_{c u}^{0.57} .
$$

According to the S-N curve of formula (6), the fatigue damage degree of the concrete at the center pivot position was calculated. The fatigue damage of the concrete was considered when the damage degree reached 1.0.

The fatigue life of the bridge-deck concrete at different locations is presented in Table 7. The fatigue life of the concrete at different locations was $>100$ years when the loading position was $1.0 \mathrm{~m}$ from the centerline of the bridge. When the loading position was $7.0 \mathrm{~m}$ from the centerline of the bridge, the fatigue life of the cross-beam concrete was $>100$ years, while that of the midspan concrete was only 37 years. Therefore, the fatigue stress of the concrete at the midspan was the most disadvantageous when the loading position was $7.0 \mathrm{~m}$ from the centerline of the bridge.

\subsection{Effect of Lane Position on Fatigue of Reinforcement Bars in} Bridge Deck. According to the analysis presented in Section 4.2 , the distance between the centerline of the lane and the most unfavorable fatigue position should be considered when deciding the layout of the lanes because of the different stress properties of the bridge deck in the transverse direction. Three different lane positions were selected to analyze the effect of the lane layout on the fatigue of bridgedeck reinforcement. Dazhenggang is a double-span bridge with four lanes in one direction. Half of the bridge structure was selected for the analysis. If the width of each lane is $3.75 \mathrm{~m}$ and the total width of lanes that can be arranged on the half-deck is $9 \mathrm{~m}$, there are two lanes in each half-deck. Three different transverse positions were selected for the lane layout, as shown in Figures 17(a)-17(c).

The wheel positions and wheel distribution ranges for various working conditions are presented in Table 8.

According to the analysis presented in Section 4.2, the locations of the left wheel of Lane 1 and the right wheel of Lane 2 are close to the most unfavorable position of the lateral force. The bridge deck $1.0 \mathrm{~m}$ from the centerline of the bridge does not experience fatigue damage. Therefore, the bridge deck under the left wheel of Lane 1 was not analyzed; only the fatigue damage of the right wheel of Lane 2 was analyzed. The highest position of the wheel distribution frequency under various working conditions is presented in Table 9.

The fatigue damage at the most unfavorable transverse position of the bridge deck, that is, $7.0 \mathrm{~m}$ from the centerline of the bridge, and that at the highest frequency of wheels were compared. The results are presented in Table 10.

In working condition 1 , the fatigue damage was high owing to the overlap of the lane centerline and the most disadvantageous position of the deck. However, in working conditions 2 and 3, the probability of driving in the most unfavorable position was reduced because the distance between the centerline of the lane and the most unfavorable position of the deck under stress was approximately $1.0 \mathrm{~m}$, which significantly reduced the fatigue damage of the reinforcement. At the position $7.0 \mathrm{~m}$ from the centerline of the bridge, the damage degrees of conditions 2 and 3 were $56.2 \%$ and $61.8 \%$ of that of condition 1 , respectively. The 
TABLE 6: Fatigue life of reinforcement bars.

\begin{tabular}{lccc}
\hline Check position of reinforcement & Distance between loading position and bridge centerline (m) & \multicolumn{2}{c}{ Fatigue life } \\
& & ECCS100 [16] & BS5400 [13] \\
\hline Midspan & 1.0 & $>100$ & $>100$ \\
Beam & & $>100$ & $>100$ \\
Midspan & 7.0 & 15 & 7 \\
Beam & & $>100$ & 44 \\
\hline
\end{tabular}

TABLe 7: Fatigue life of the bridge-deck concrete.

\begin{tabular}{lcc}
\hline Checking calculation position of bridge-deck concrete & Distance between loading position and bridge centerline (m) & Fatigue life \\
\hline Midspan & 1.0 & $>100$ \\
Beam & & $>100$ \\
Midspan & 7.0 & 37 \\
Beam & & $>100$ \\
\hline
\end{tabular}

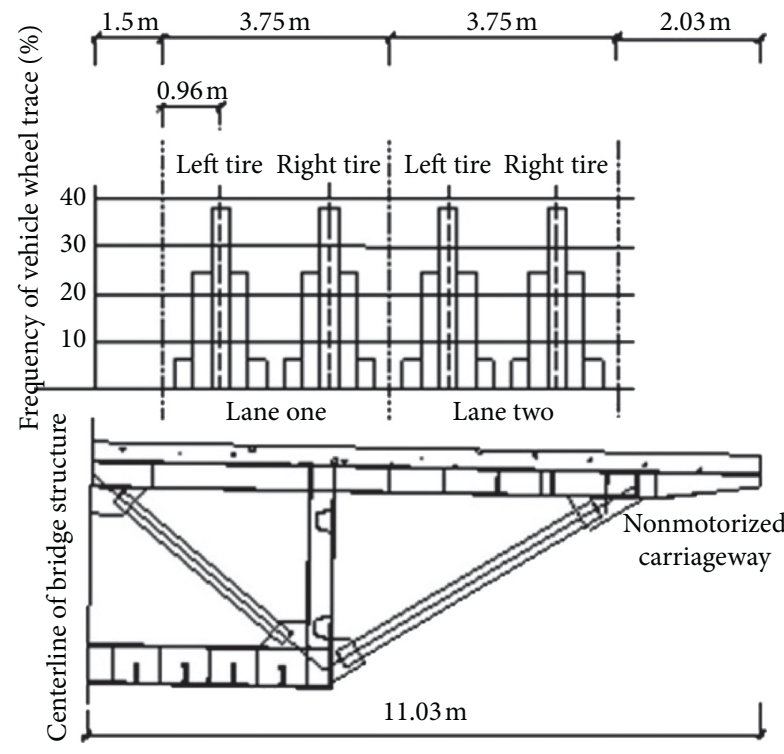

(a)

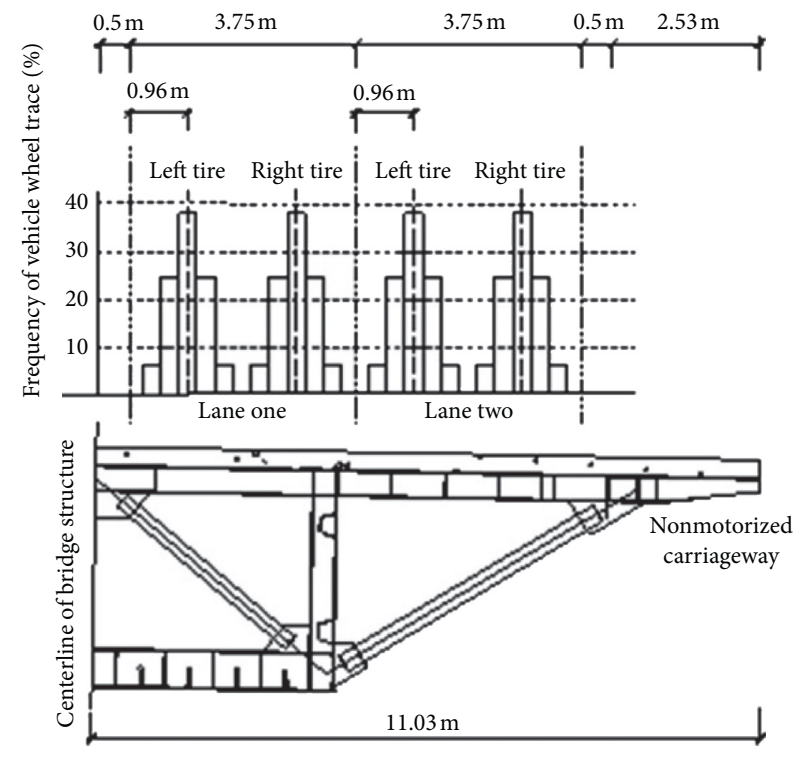

(b)

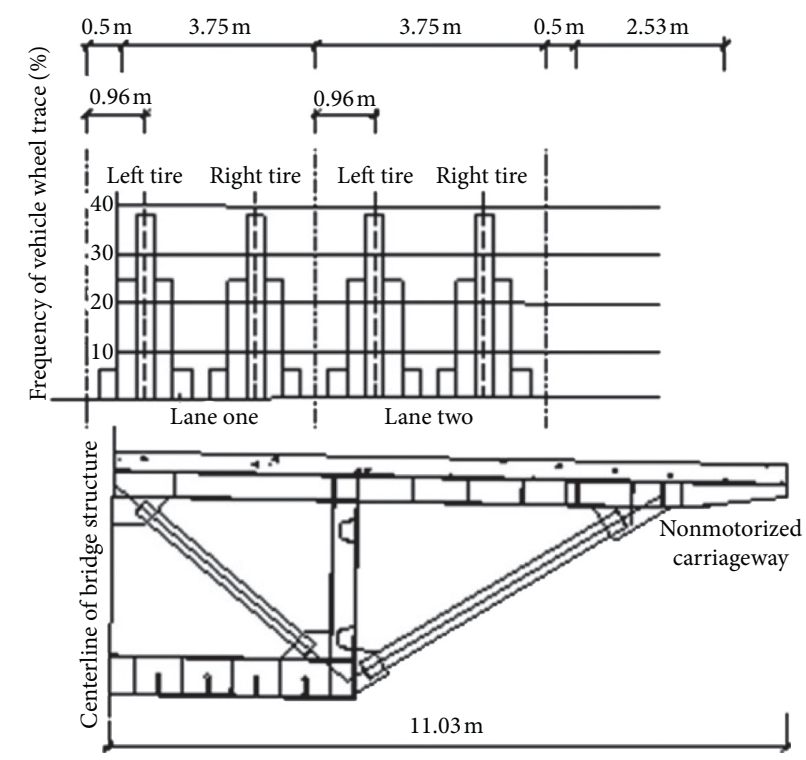

(c)

FiguRE 17: Transverse distribution frequency of wheels for different lane arrangements. (a) The distance between the left tire and lane one is $0.96 \mathrm{~m}$; (b) the distance between the left tire and lane two is $0.96 \mathrm{~m}$; (c) the distances between the left tire and the center line of bridge structure, the left tire and lane two both are $0.96 \mathrm{~m}$. 
TABLE 8: Distribution ranges of lanes and wheels under various working conditions.

\begin{tabular}{lccc}
\hline & & Distance from bridge centerline $(\mathrm{m})$ & \\
& Working condition 1 & Working condition 2 & Working condition 3 \\
\hline Lane 1 & $0.5 \sim 4.25$ & $1.5 \sim 5.25$ & $-0.5 \sim 3.25$ \\
Lane 1, left wheel & $0.725 \sim 2.225$ & $1.725 \sim 3.225$ & $-0.275 \sim 1.225$ \\
Lane 1, right wheel & $2.525 \sim 4.025$ & $3.525 \sim 5.025$ & $1.525 \sim 3.025$ \\
Lane 2 & $4.25 \sim 8.0$ & $5.25 \sim 9.0$ & $3.25 \sim 7.0$ \\
Lane 2, left wheel & $4.475 \sim 5.975$ & $5.475 \sim 6.975$ & $3.475 \sim 4.975$ \\
Lane 2, right wheel & $6.275 \sim 7.775$ & $7.275 \sim 8.775$ & $5.275 \sim 6.775$ \\
\hline
\end{tabular}

TABLE 9: Distance between the maximum frequency position of wheel and the centerline of the bridge under various working conditions.

\begin{tabular}{lccc}
\hline & \multicolumn{3}{c}{ Distance between maximum frequency of wheel and center line of bridge (m) } \\
& Working condition 1 & Working condition 2 & Working condition 3 \\
\hline Lane 2, right wheel & $6.875 \sim 7.175$ & $7.875 \sim 8.175$ & $5.875 \sim 6.175$ \\
\hline
\end{tabular}

TABLE 10: Damage degrees under various working conditions.

\begin{tabular}{|c|c|c|c|c|c|c|}
\hline \multirow{2}{*}{ Year } & \multicolumn{3}{|c|}{$\begin{array}{c}\text { On the beam } 7.0 \mathrm{~m} \text { from the centerline of the bridge } \\
\text { Cumulative damage degree }\end{array}$} & \multicolumn{3}{|c|}{$\begin{array}{l}\text { On the beam with the highest wheel frequency } \\
\text { Cumulative damage degree }\end{array}$} \\
\hline & $\begin{array}{c}\text { Working condition } \\
1\end{array}$ & $\begin{array}{c}\text { Working condition } \\
2\end{array}$ & $\begin{array}{l}\text { Working condition } \\
3\end{array}$ & $\begin{array}{c}\text { Working condition } \\
1\end{array}$ & $\begin{array}{c}\text { Working condition } \\
2\end{array}$ & $\begin{array}{c}\text { Working condition } \\
3\end{array}$ \\
\hline 2010 & 0.01 & 0.01 & 0.01 & 0.01 & 0.01 & 0.01 \\
\hline 2020 & 0.16 & 0.09 & 0.10 & 0.16 & 0.09 & 0.11 \\
\hline 2030 & 0.39 & 0.22 & 0.24 & 0.39 & 0.22 & 0.26 \\
\hline 2040 & 0.65 & 0.37 & 0.40 & 0.65 & 0.37 & 0.43 \\
\hline 2050 & 0.92 & 0.52 & 0.57 & 0.92 & 0.52 & 0.60 \\
\hline 2060 & 1.18 & 0.66 & 0.73 & 1.18 & 0.67 & 0.78 \\
\hline 2110 & 2.49 & 1.40 & 1.54 & 2.49 & 1.42 & 1.64 \\
\hline \multirow{2}{*}{ Year } & \multicolumn{3}{|c|}{$\begin{array}{c}\text { Midspan of } 7.0 \mathrm{~m} \text { from the centerline of the bridge } \\
\text { Cumulative damage degree }\end{array}$} & \multicolumn{3}{|c|}{$\begin{array}{l}\text { Midspan at the highest wheel frequency } \\
\text { Cumulative damage degree }\end{array}$} \\
\hline & $\begin{array}{c}\text { Working condition } \\
1\end{array}$ & $\begin{array}{c}\text { Working condition } \\
2\end{array}$ & $\begin{array}{l}\text { Working condition } \\
3\end{array}$ & $\begin{array}{c}\text { Working condition } \\
1\end{array}$ & $\begin{array}{l}\text { Working condition } \\
2\end{array}$ & $\begin{array}{c}\text { Working condition } \\
3\end{array}$ \\
\hline 2010 & 0.11 & 0.06 & 0.07 & 0.11 & 0.07 & 0.06 \\
\hline 2020 & 1.57 & 0.89 & 0.97 & 1.57 & 1.11 & 0.94 \\
\hline 2030 & 3.77 & 2.13 & 2.33 & 3.77 & 2.66 & 2.26 \\
\hline 2040 & 6.29 & 3.55 & 3.89 & 6.29 & 4.44 & 3.77 \\
\hline 2050 & 8.82 & 4.98 & 5.45 & 8.82 & 6.22 & 5.28 \\
\hline 2060 & 11.34 & 6.40 & 7.01 & 11.34 & 8.00 & 6.80 \\
\hline 2110 & 23.97 & 13.53 & 14.81 & 23.97 & 16.91 & 14.36 \\
\hline
\end{tabular}

amount of damage at the most disadvantageous position under the static stress of the bridge deck was smaller than the amount of fatigue damage at the highest wheel frequency. Therefore, if the influence of lane position on fatigue is considered, the service life of bridge deck can be significantly improved.

5.4. Effects of Reinforcement Ratio and Thickness of Bridge Deck on Bridge-Deck Fatigue. The tensile fatigue of the steel bar in the deck and the punching fatigue of the concrete are significantly affected by the thickness of the deck and reinforcement ratio of the steel bar [57]. According to the analysis results presented in Section 4.2, both the reinforcement and the concrete of the concrete deck $7.0 \mathrm{~m}$ from the centerline of the bridge will have suffered fatigue damage within 100 years. In this section, the bridge deck is taken as the research object. The S-N curve of BS5400 [22] is used for calculations, and the parameters shown in Table 11 are used.
TABLE 11: Selected calculation parameters.

\begin{tabular}{lc}
\hline Reinforcement ratio $(\%)$ & $1.76,2.50,3$ \\
\hline Slab thickness $(\mathrm{cm})$ & $25,30,35$ \\
\hline
\end{tabular}

Three reinforcement ratios and fatigue damage degrees of the concrete and reinforcement under three slab thicknesses are selected for comparison, which provides a useful reference for the design of the bridge deck.

As shown in Figures 18-20 and Table 12, the fatigue life of the deck reinforcement significantly increased with an increase in the reinforcement ratio. At a slab thickness of $<30 \mathrm{~cm}$, even when the reinforcement ratio reached $3 \%$, the fatigue life of the deck reinforcement was $<50$ years, which was significantly shorter than the 100-year design life of the bridge (Table 12). At a slab thickness of $35 \mathrm{~cm}$, when the reinforcement ratio reached $3 \%$, the fatigue life of the steel 


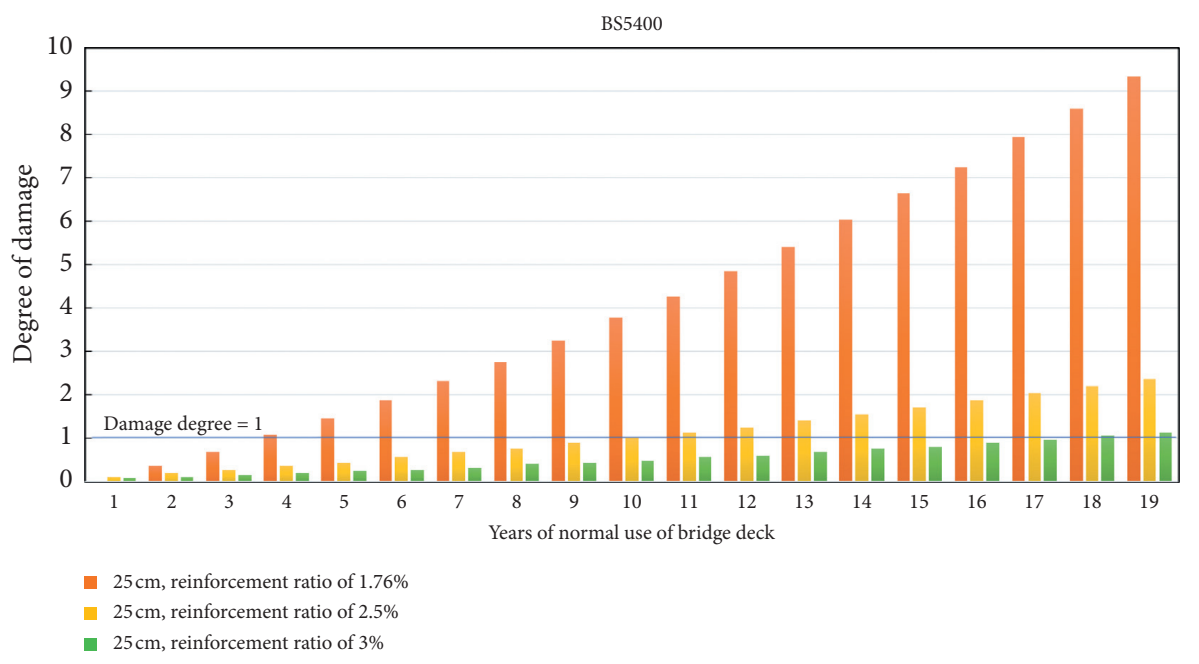

FIGURE 18: Fatigue damage of bridge-deck reinforcement under three reinforcement ratios with a slab thickness of $25 \mathrm{~cm}$.

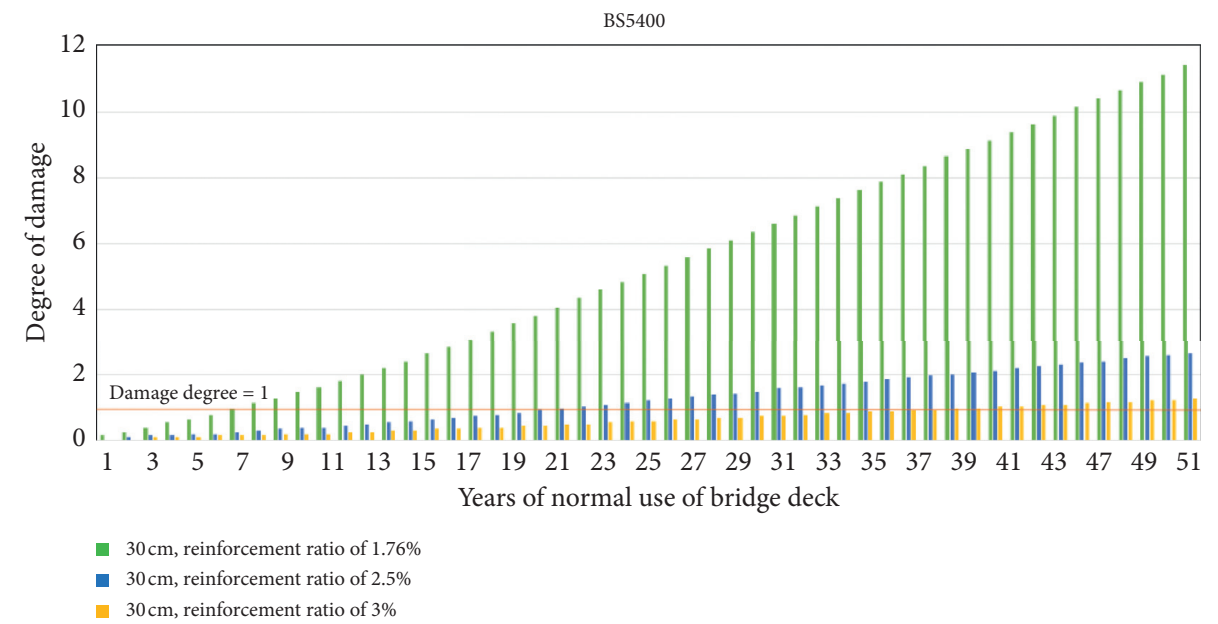

FIGURE 19: Fatigue damage of bridge-deck reinforcement under three reinforcement ratios with a slab thickness of $30 \mathrm{~cm}$.

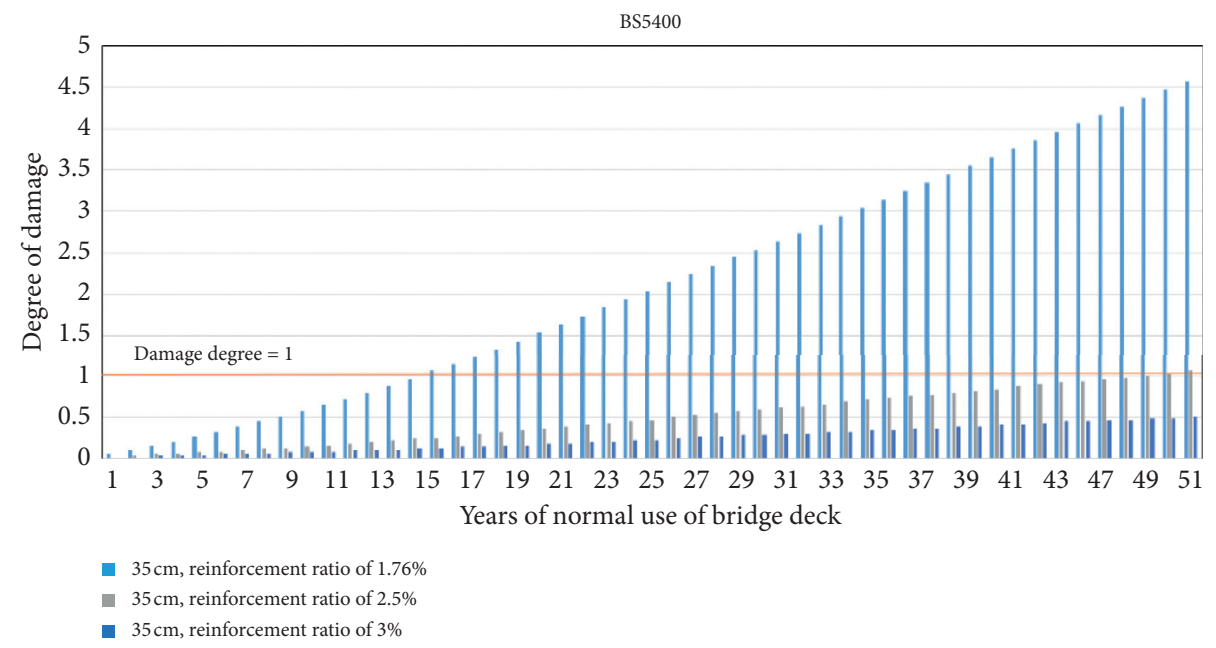

Figure 20: Fatigue damage of bridge-deck reinforcement under three reinforcement ratios with a slab thickness of $35 \mathrm{~cm}$. 
TABle 12: Reinforcement life of the deck under different slab thicknesses and reinforcement ratios.

\begin{tabular}{lcc}
\hline Slab thickness $(\mathrm{cm})$ & Reinforcement ratio (\%) & Life (years) \\
\hline \multirow{3}{*}{25} & 1.76 & 3 \\
& 2.5 & 10 \\
3 & 1.76 & 28 \\
30 & 2.5 & 7 \\
& 3 & 33 \\
& 1.76 & 52 \\
35 & 2.5 & 25 \\
& 3 & 59 \\
& & 101 \\
\hline
\end{tabular}

TABle 13: Punching fatigue life of the bridge-deck concrete under different slab thicknesses and reinforcement ratios.

\begin{tabular}{ccc}
\hline Slab thickness $(\mathrm{cm})$ & Reinforcement ratio (\%) & Life (years) \\
\hline \multirow{3}{*}{25} & 1.76 & 5 \\
& 2.5 & 18 \\
& 3.0 & 34 \\
30 & 1.76 & 37 \\
& 2.5 & $>100$ \\
& 3.0 & $>100$ \\
35 & 1.76 & $>100$ \\
& 2.5 & $>100$ \\
& 3.0 & $>100$ \\
\hline
\end{tabular}

bar in the deck reached 101 years, which was longer than the design life of the bridge (Table 12).

The relationships between the punching fatigue life of the bridge deck and the reinforcement ratio and slab thickness are presented in Table 13. Increasing the reinforcement ratio was effective for restraining the punching fatigue damage to the bridge-deck concrete. When the slab thickness was $25 \mathrm{~cm}$ and the reinforcement ratio was $1.76 \%$, the punching fatigue life of the bridge-deck concrete was only 5 years. Even when the reinforcement ratio reached 3\%, the punching fatigue life of the deck concrete was only 34 years, which was significantly lower than the 100 -year design life of the bridge (Table 13). When the slab thickness was $\geq 30 \mathrm{~cm}$ and the reinforcement ratio was $\geq 2.5 \%$, the punching fatigue life of the bridge-deck concrete was $>100$ years and was longer than the bridge design life.

In conclusion, when the slab thickness of the bridge deck is $<30 \mathrm{~cm}$, the effects of increasing the reinforcement ratio on the fatigue life of the bridge-deck reinforcement and the punching shear fatigue life of the concrete are not obvious, and the increase in fatigue life is negligible in comparison with the 100-year design life of the bridge. For a $35 \mathrm{~cm}$ thick bridge deck, even a reinforcement ratio of $1.76 \%$ will not cause fatigue damage. Therefore, the concrete slab thickness of the bridge deck is recommended to be $\geq 35 \mathrm{~cm}$, which complies with the strict requirement for the thickness of the concrete bridge deck in the Japanese Road specification [58].

\section{Conclusion}

According to a load investigation, a fatigue assessment method for a composite beam bridge deck was proposed, and the fatigue damage and life for steel bar tension fatigue and concrete punching shear fatigue of a composite beam $\mathrm{RC}$ bridge deck were calculated. The following conclusions are drawn:

(1) When the centerline of the wheel track swings laterally on the same lane for approximately $1.5 \mathrm{~m}$, it has little influence on the force of the deck. The effect of the wheel track position can be ignored in the fatigue checking of the deck.

(2) For the deck of the steel-concrete composite beam, the fatigue properties of the steel bar and concrete in the deck depend significantly on the transverse loading position. The fatigue life of the deck at different positions is $>100$ years when the loading position is $1.0 \mathrm{~m}$ from the centerline of the bridge. The fatigue life of the concrete across the middle span is only 37 years when the loading position is $7.0 \mathrm{~m}$ from the centerline of the bridge. Therefore, the fatigue stress of the concrete on the bridge deck is the most disadvantageous when the loading position is $7.0 \mathrm{~m}$ from the centerline of the bridge.

(3) The lane arrangement significantly affects the fatigue damage of the bridge deck; thus, the overlap of the lane centerline and the most unfavorable stress position should be avoided to the greatest extent possible. The fatigue damage is reduced by $30 \%-40 \%$ when the centerline of the lane deviates from the most unfavorable stress position by $1 \mathrm{~m}$.

(4) The reinforcement ratio and thickness of the deck have similar effects on the fatigue life of deck reinforcement, and the punching fatigue of the concrete is more sensitive to changes in the thickness of the deck. When the deck thickness is $<30 \mathrm{~cm}$, the effects of increasing the reinforcement ratio on the fatigue life of the deck reinforcement and the punching fatigue life of the concrete are not obvious, and the increase in fatigue life is negligible in comparison with the 100 -year design life of the bridge. For $35 \mathrm{~cm}$ thick decks, even a reinforcement ratio of $1.76 \%$ will not cause fatigue damage. The thickness of the concrete slab of the bridge deck is recommended to be $\geq 35 \mathrm{~cm}$. 


\section{Data Availability}

The data used to support the findings of this study are not available.

\section{Conflicts of Interest}

The authors declare that they have no conflicts of interest.

\section{Acknowledgments}

This work was supported by the National Natural Science Foundation of China (no. 51878623), Innovative Research Team (in Science and Technology) in University of Henan Province (no. 20IRTSTHN009), Program for Young Backbone Teachers in Colleges and Universities in Henan (no. 2018GGJS005), and Foundation for Postdoctoral Students in Henan Province (no. 1901024).

\section{References}

[1] Z. Zhu, Z. Xiang, and Y. E. Zhou, "Fatigue behavior of orthotropic steel bridge stiffened with ultra-high performance concrete layer," Journal of Constructional Steel Research, vol. 157, pp. 132-142, 2019.

[2] Q. Zhang, Y. Liu, Y. Bao, D. Jia, Y. Bu, and Q. Li, "Fatigue performance of orthotropic steel-concrete composite deck with large-size longitudinal U-shaped ribs," Engineering Structures, vol. 150, pp. 864-874, 2017.

[3] Q. Liu, X. Li, X. Zhang, Y. Zhou, and Y. F. Chen, "Applying constrained layer damping to reduce vibration and noise from a steel-concrete composite bridge: an experimental and numerical investigation," Journal of Sandwich Structures and Materials, vol. 22, no. 6, pp. 1743-1769, 2020.

[4] Y. Lu and L. Ji, "Behavior of optimized prestressed concrete composite box-girders with corrugated steel webs," Steel and Composite Structures, vol. 26, pp. 183-196, 2018.

[5] K. Shen, S. Wan, Y. Mo, and X. Li, "A softened membrane model for prestressed concrete composite box girders with corrugated steel webs under pure torsion," Advances in Structural Engineering, vol. 22, no. 2, pp. 384-401, 2019.

[6] P. Gao, K. Li, Y. Zheng, and G. Golewski, "Experimental study on fatigue performance of negative bending moment of steelconcrete continuous composite box girder," Advances in Civil Engineering, vol. 2020, Article ID 8879746, 17 pages, 2020.

[7] A. G. Soto, A. P. Caldentey, H. C. Peiretti, and J. C. Benítez, "Experimental behaviour of steel-concrete composite box girders subject bending, shear and torsion," Engineering Structures, vol. 206, Article ID 110169, 2020.

[8] J. Nie and C. S. Cai, "Steel-concrete composite beams considering shear slip effects," Journal of Structural Engineering, vol. 129, no. 4, pp. 495-506, 2003.

[9] R. Walter, J. F. Olesen, H. Stang, and T. Vejrum, "Analysis of an orthotropic deck stiffened with a cement-based overlay," Journal of Bridge Engineering, vol. 12, no. 3, pp. 350-363, 2007.

[10] Y. Liu, Q. Zhang, Y. Bao, and Y. Bu, "Fatigue behavior of orthotropic composite deck integrating steel and engineered cementitious composite," Engineering Structures, vol. 220, Article ID 111017, 2020.

[11] F. Leonhardt, A. W. Andr, A. H. P. Andr et al., "Zur bemessung durchlaufender verbundtraeger bei dynamischer belastung," Bauingenieur Der, vol. 62, 1987.
[12] M. G. Navarro and J.-P. Lebet, "Concrete cracking in composite bridges: tests, models and design proposals," Structural Engineering International, vol. 11, no. 3, pp. 184-190, 2001.

[13] A. Muttoni and F. Ruiz, "Concrete cracking in tension members and application to deck slabs of bridges," Journal of Bridge Engineering, vol. 12, no. 5, pp. 646-653, 2007.

[14] C. Zanuy, P. de la Fuente, and L. Albajar, "Estimation of parameters defining negative tension stiffening," Engineering Structures, vol. 32, no. 10, pp. 3355-3362, 2010.

[15] C. Zanuy and G. Ulzurrún, "Simplified approach for assessing shear resistance of reinforced concrete beams under impact loads," ACI Structural Journal, vol. 114, no. 3, pp. 789-791, 2017.

[16] G. Yao and X. Xiong, "Test and finite element study on static behaviors of unbonded prestressed steel reinforced concrete frame beams," Journal of Building Structures, vol. 40, pp. 104-112, 2019.

[17] W. Lin and T. Yoda, "Mechanical behaviour of composite girders subjected to hogging moment: experimental study," Journal of Japan Society of Civil Engineers, Ser. A1 (Structural Engineering \& Earthquake Engineering (SE/EE)), vol. 67, no. 3, pp. 583-596, 2011.

[18] S. Chen, X. Wang, and Y. Jia, "A comparative study of continuous steel-concrete composite beams prestressed with external tendons: experimental investigation," Journal of Constructional Steel Research, vol. 65, no. 7, pp. 1480-1489, 2009.

[19] J. P. Lin, J. F. Wang, and R. Q. Xu, "Cohesive zone model based numerical analysis of steel-concrete composite structure push-out tests," Mathematical Problems in Engineering, vol. 2014, Article ID 175483, 12 pages, 2014.

[20] A. El-Zohairy, H. Salim, and A. Saucier, "Steel-Concrete composite beams strengthened with externally post-tensioned tendons under fatigue," Journal of Bridge Engineering, vol. 24, no. 5, Article ID 04019027, 2019.

[21] Specifications for Design of Highway Steel Bridge, JTG D642015, 2015.

[22] British Standards Institution, Code of Practice for Design of Composite bridges BS 5400 Steel, Concrete, and Composite Bridges, British Standards Institution, London, UK, 1979.

[23] R. Xiu, M. Spiryagin, Q. Wu, S. Yang, and Y. Liu, "Fatigue life assessment methods for railway vehicle bogie frames," Engineering Failure Analysis, vol. 116, Article ID 104725, 2020.

[24] D. Gao, Z. Gu, H. Zhu, and Y. Huang, "Fatigue behavior assessment for steel fiber reinforced concrete beams through experiment and fatigue prediction model," Structures, vol. 27, pp. 1105-1117, 2020.

[25] ECCS-European Convention, Fatigue Design of Steel and Composite Structures: Eurocode 3: Design of Steel Structures: Part 1-9, ECCS, Ernst \& Sohn, Berlin, Germany, 2011.

[26] AASHTO LRFD Bridge Design Specifications: Customary U.S. Units, $4^{\text {th }}$ Edition, 2007.

[27] M. A. Miner, "Cumulative damage in fatigue Jour," Journal of Applied Mechanics, vol. 12, 1945.

[28] T. Nishida, T. Shiotani, H. Asaue, T. Maejima, and Y. Kobayashi, "Damage evaluation of RC bridge deck under wheel loading test by means of AE tomography," Journal of Acoustic Emission, vol. 34, pp. S26-S31, 2017.

[29] C. Shan and Y. Yi, "Stress concentration analysis of an orthotropic sandwich bridge deck under wheel loading," Journal of Constructional Steel Research, vol. 122, pp. 488-494, 2016.

[30] C. Solae, M. G. Chorzepa, S. A. Durham, and S. S. Kim, "Investigation of cracks observed on a skewed bridge 
constructed using self-propelled modular transporters," Journal of Performance of Constructed Facilities, vol. 34, 2020.

[31] G. Fu, Y. Zhuang, and J. Feng, "Behavior of reinforced concrete bridge decks on skewed steel superstructure under truck wheel loads," Journal of Bridge Engineering, vol. 16, no. 2, pp. 219-225, 2011.

[32] L. Henze, G. A. Rombach, and M. Harter, "New approach for shear design of reinforced concrete slabs under concentrated loads based on tests and statistical analysis," Engineering Structures, vol. 219, Article ID 110795, 2020.

[33] Z. Zhu, T. Yuan, Z. Xiang, Y. Huang, Y. E. Zhou, and X. Shao, "Behavior and fatigue performance of details in an orthotropic steel bridge with UHPC-deck plate composite system under in-service traffic flows," Journal of Bridge Engineering, vol. 23, 2018.

[34] X. Y. Zhou, M. Treacy, F. Schmidt et al., "Effect on bridge load effects of vehicle transverse in-lane position: a case study," Journal of Bridge Engineering, vol. 20, no. 12, Article ID 04015020, 2015.

[35] G. Zeng, W. Xu, and H. Huang, "Study of the strain response of asphalt pavements on orthotropic steel bridge decks through field testing and numerical simulation," Journal of Testing and Evaluation, vol. 48, pp. 1-19, 2020.

[36] Z. Fu, Y. Wang, B. Ji, and F. Jiang, "Effects of multiaxial fatigue on typical details of orthotropic steel bridge deck," ThinWalled Structures, vol. 135, pp. 137-146, 2019.

[37] X. Xu, X. Yang, W. Huang, H. Xiang, and W. Yang, "New damage evolution law for steel-asphalt concrete composite pavement considering wheel load and temperature variation," Materials, vol. 12, no. 22, 2019.

[38] B. Belletti, C. Damoni, M. A. N. Hendriks, and A. de Boer, "Analytical and numerical evaluation of the design shear resistance of reinforced concrete slabs," Structural Concrete, vol. 15, no. 3, pp. 317-330, 2014.

[39] V. Adam, M. Herbrand, and M. Classen, "Experimentelle untersuchungen zum einfluss der bauteilbreite und der schubschlankheit auf die querkrafttragfähigkeit von stahlbetonplatten ohne querkraftbewehrung/experimental investigations on the influence of the slab width and the momentshear-ratio on the shear capacity of rc slabs without shear reinforcement," Bauingenieur, vol. 93, no. 1, pp. 37-45, 2018.

[40] M. E. Shoukry, Z. I. Mahmoud, T. M. Hashem, and G. A. Mohamed, "Flexural analysis of RC rectangular slabs subjected to patch load," Alexandria Engineering Journal, vol. 57, no. 4, pp. 3273-3279, 2018.

[41] J. R. Martí-Vargas, "Discussion of "effect of reinforcement ratio on transverse early-age cracking of GFRP-RC bridge deck slabs" by amir ghatefar, ehab el-salakawy, and M. T. Bassuoni," Journal of Composites for Construction, vol. 19, no. 1, Article ID 07014001, 2015.

[42] A. Ghatefar, E. El-Salakawy, and M. T. Bassuoni, "Early-age restrained shrinkage cracking of GFRP-RC bridge deck slabs: effect of environmental conditions," Cement and Concrete Composites, vol. 64, pp. 62-73, 2015.

[43] A. Ghatefar, E. El-Salakawy, and M. T. Bassuoni, "Effect of reinforcement ratio on transverse early-age cracking of GFRP-RC bridge deck slabs," Journal of Composites for Construction, vol. 18, no. 6, Article ID 04014018, 2014.

[44] S. Wei, Z. Zhang, S. Li, and H. Li, "Strain features and condition assessment of orthotropic steel deck cable-supported bridges subjected to vehicle loads by using dense FBG strain sensors," Smart Materials and Structures, vol. 26, no. 10, Article ID 104007, 2017.
[45] Q. Su, C. Dai, and C. Xu, "Full-scale experimental study on the negative flexural behavior of orthotropic steel-concrete composite bridge deck," Journal of Bridge Engineering, vol. 23, 2018.

[46] V. G. Rao and S. Talukdar, "Prediction of fatigue life of a continuous bridge girder based on vehicle induced stress history," Shock \& Vibration, vol. 10, no. 5-6, pp. 325-338, 2003.

[47] Y. Chen, J. Dong, Z. Tong, R. Jiang, and Y. Yue, "Flexural behavior of composite box girders with corrugated steel webs and trusses," Engineering Structures, vol. 209, Article ID 110275, 2020.

[48] P. Gao, Q. T. Su, C. Wu, Y. M. Sun, and H. Y. Liu, "Fatigue performance of deck slab under hogging moment in continuous composite girder bridge," Advanced Materials Research, vol. 255-260, no. 255-260, pp. 1142-1146, 2011.

[49] D. Fall and T. Petersson, "Fatigue assessment methods for bridges according to eurocode: program development and comparative study of design methods," Master Dissertation, Chalmers University of Technology, Goteborg, Sweden, 2009.

[50] Z. Ye, B.-H. Ji, Z. Yuanzhou, and Z.-Q. Fu, "Investigation of the fatigue vehicle load for a long-span steel bridge based on nine years of measured traffic data," Structural Engineering International, pp. 1-9, 2020.

[51] T. Zarrin-Ghalami and A. Fatemi, "Cumulative fatigue damage and life prediction of elastomeric components," Fatigue \& Fracture of Engineering Materials \& Structures, vol. 36, pp. 270-279, 2013.

[52] M. Khakzar, A. Rakotonirainy, A. Bond et al., "A dual learning model for vehicle trajectory prediction," IEEE Access, vol. 99, p. 1, 2020.

[53] Z. X. Li, T. H. T. Chan, and J. M. Ko, "Fatigue damage model for bridge under traffic loading: application made to Tsing $\mathrm{Ma}$ bridge," Theoretical and Applied Fracture Mechanics, vol. 35, no. 1, pp. 81-91, 2001.

[54] Aviation University of South Florida, "Airport pavement design and evaluation," Department of Transportation Advisory Circular, vol. 159, 1981.

[55] S. Matsui, "Fatigue strength of RC-slabs of highway bridge by wheel running machine and influence of water on fatigue," Proceedings of JCI, vol. 9, pp. 627-632, 1987.

[56] G. Zhenhai and S. Xudong, Theory and Analysis of Reinforced Concrete, Tsinghua University Press, Beijing, China, 2005.

[57] X. Shao, D. Yi, Z. Huang, H. Zhao, B. Chen, and M. Liu, "Basic performance of the composite deck system composed of orthotropic steel deck and ultrathin RPC layer," Journal of Bridge Engineering, vol. 18, no. 5, pp. 417-428, 2013.

[58] Japan Road Association, Design Specifications of Highway Bridges. Part V: Seismic Design, Japan Road Association, Tokyo. Japan, 2002. 